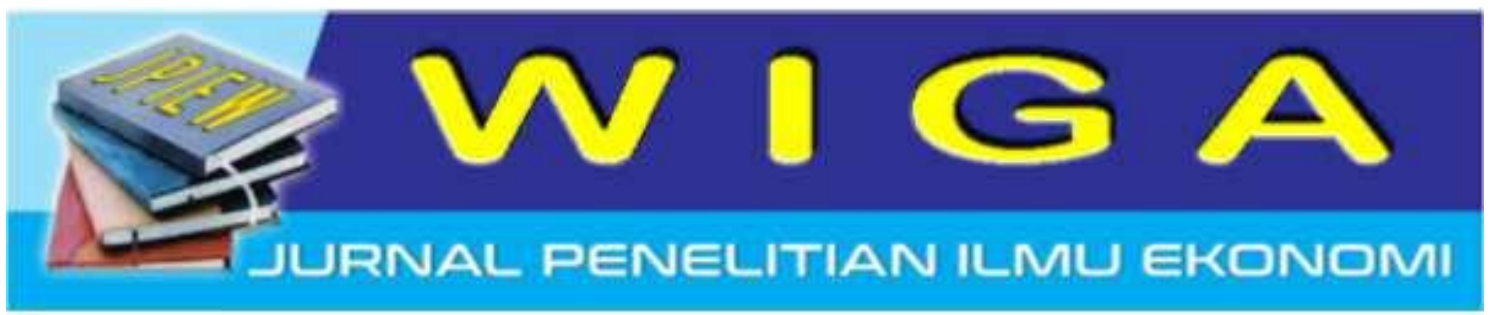

\title{
Strategi Sektor Kesehatan Dalam Meningkatkan Indeks Pembangunan Manusia Di Kabupaten Situbondo
}

\author{
Arif Tristanto \\ STIE Mandala Jember \\ email: ariftristan21@gmail.com \\ Herman Cahyo Diartho \\ Universitas Jember \\ email: hermancahyodiartho@yahoo.com
}

\begin{abstract}
Abstrak
Keberhasilan suatu pembangunan tidak hanya dilihat dari tingkat pertumbuhan ekonomi akan tetapi juga dari tingkat kesejahteraan masyarakat juga menjadi tolak ukur keberhasilan pembangunan suatu daerah. Indeks Pembangunan manusia melingkupi tiga indeks yaitu indeks pendidikan, indeks kesehatan, dan indeks daya beli. Pada penelitian ini mengambil salah satu indikator dalam meningkatkan indeks pembangunan manusia yaitu indeks kesehatan. Dilihat dari tingkat pertumbuhan indeks pembangunan manusia (IPM) Kabupaten Situbondo pertumbuhan indeks kesehatan selama tahun 2012-2016 tetap sebesar 0.74 dan perumbuhan indeks pembangunan manusia (IPM) di Kabupaten Situbondo masih dibawah pertumbuhan indeks pembangunan manusia (IPM) di Provinsi Jawa Timur. Rumusan masalah yang diambil dalam penelitian ini adalah bagaimana sintesa strategi dalam meningkatkan Indeks Pembangunan Manusia (IPM) di sektor kesehatan di Kabupaten Situbondo. Metode analisis yang digunakan menggunakan analytical hierarchy process. Hasil analisis analisis diperoleh strategi yang digunakan dalam meningkatkan indeks pembangnan manusia di Kabupaten Situbondo pada sektor kesehatan yaitu pelayanan kesehatan menjadi prioritas dalam peningkatan indeks pembangunan manusia sektor kesehatan di Kabupaten Situbondo sebesar 0,136, dan kedua anggaran kesehatan sebesar 0,059, dan ketiga kelembagaan sektor kesehatan sebesar 0,018 .
\end{abstract}

Kata kunci: IPM, Sektor Kesehatan, AHP, Kabupaten Situbondo.

\section{Abstract}

The success of a development is not only seen from the level of economic growth but also from the level of community welfare as well as a benchmark for the success of the development of a region. The Human Development Index covers three indices, namely the 
education index, health index, and purchasing power index. In this study one of the indicators in improving the human development index is the health index. Judging from the growth rate of the Situbondo District human development index (HDI), the health index growth during 2012-2016 remained at 0.74 and the growth of the human development index (HDI) in Situbondo was still below the growth of the human development index (HDI) in East Java Province. The formulation of the problem taken in this study is how to synthesize strategies in improving the Human Development Index (HDI) in the health sector in Situbondo District. The analytical method used uses analytical hierarchy process. The results of the analysis analysis obtained the strategy used in improving the human development index in Situbondo District in the health sector, namely health services became a priority in improving the human development index in the health sector in Situbondo District by 0.136, and both health budgets by 0.059, and the three health sector institutions by 0.018 .

\section{Keyword : HDI, Health Sector, AHP, Situbondo District.}

\section{PENDAHULUAN}

Perkembangan pembangunan saat ini, dalam paradigma baru suatu pembangunan bukan hanya menitikberatkan pada pertumbuhan ekonomi melainkan juga menitikberatkan pada pembangunan manusia sebagai dasar keberhasilan pembangunan suatu Negara maupun daerah/wilayah. Pembangunan manusia itu sendiri merupakan pembangunan yang dilakukan untuk meningkatkan tingkat kesejahteraan masyarakat dalam suatu wilayah atau daerah, dengan tingkat kesejahteraan yang tinggi maka dengan secara tidak langsung dapat meningkatkan pertumbuhan ekonomi suatu wilayah atau daerah. Pembangunan manusia dapat diwujudkan dengan menekankan pada terpenuhinya kehidupan layak bagi manusia dan kebutuhan dasarnya. Kebutuhan dasar dalam untuk masyarakat pada suatu Negara ataupun daerah adalah kebutuhan kesehatan, pendidikan,dan kebutuhan ekonomi. Pembangunan manusia menurut Human Development Report dalam Indeks Pembangunan Manusia Indonesia (2017), pembangunan manusia merupakan suatu proses perluasan pilihan masyarakat, pada prinsipnya bahwa pilihan masyarakat sangat banyak dan dapat berubah setiap saat. Namun pada level pembangunan ada tiga pihan kebutuhan dasar yaitu untuk berumur panjang dan hidup sehat, untuk memperoleh pendidikan dan untuk memiliki akses terhadap sumber-sumber kebutuhan agar hidup secara layak.

Dasar pembangunan daerah sudah dilakukan oleh pemerintah daerah sendiri, hal itu terkait dengan di berlakukannya undang-undang otonomi daerah yang telah diterapkan pemerintah pusat. Dasar kewenangan pemerintah daerah dalam melakukan upaya pembangunan daerah didasarkan pada undang-undang otonomi daerah UU nomor 23 tahun 2014 yang terbaru, pada undang-undang tersebut menetapkan pemberian kewenangan otonomi daerah dalam bidang ekonomi dalam mewujudkan otonomi daerah yang luas dan pemberdayaan sumber daya setempat sesuai dengan kepentingan masyarakat daerah serta penyediaan pelayanan publik yang sesuai dengan kebutuhan dasar masyarakat daerah tersebut. Selain itu pemerintah juga diberikan kewenangan dalam desentralisasi fiscal yaitu kewenangan dalam mengatur keuangan daerah untuk anggaran belanja langsung dan belanja tidak langsung.

Pembangunan manusia di Indonesia sudah diterapkan dan dijadikan sutau kajian pembangunan daerah yang penting untuk di perhatikan oleh pemerintah, keberhasilan pembangunan di Indonesia bukan hanya dilihat pada pertumbuhan ekonomi saja melainkan pada tingkat kesejahteraan masyarakat di daerah, jika pertumbuhan ekonmi yang tinggi di ikuti dengan tingkat kesejahteraan yang meningkat berarti pertumbuhan ekonomi 
tersebut memberikan dampak yang positif terhadap kesejahteraan masyakat di daerah tersebut dan sebaliknya. Pada paper ini mengambil objek kajian di Kabupaten Situbondo merupakan salah satu Kabupaten yang berada di Provinsi Jawa timur, di Kabupaten Situbondo, pembangunan manusia yang dilakukan sudah memberikan dampak yang positif dimana pertumbuhan indeks pembangunan manusia terus meningkat meskipun perumbuhan indeks pembangunan manusia masih di bawah Provinsi Jawa Timur. Berdasarkan pertumbuhan IPM Kabupaten Situbondo dibandingkan dengan pertumbuhan IPM Provinsi Jawa Timur selama tahun 2012-2016 dimana pada tahun 2012 pertumbuhan IPM Kabupaten Situbondo sebesar 62,23\% dan Provinsi Jawa Timur sebesar 64,74\%, tahun 2013 pertumbuhan IPM Kabupaten Situbondo sebesar 63,43\% dan Provinsi Jawa Timur sebesar $67,74 \%$, tahun 2014 pertumbuhan IPM Kabupaten Situbondo sebesar 63,91\% dan Provinsi Jawa Timur sebesar 68,14\%, tahun 2015 pertumbuhan IPM Kabupaten Situbondo sebesar $64,53 \%$ dan Provinsi Jawa Timur sebesar 68,95\%, tahun 2016 pertumbuhan IPM Kabupaten Situbondo sebesar 65,08\% dan Provinsi Jawa Timur sebesar 69,74\% (Badan Pusat Statistik Kabupaten Situbondo, 2017). Peningkatan pertumbuhan indeks pembangunan manusia tersebut tidak terlepas peran pemerintah dalam anggaran belanja langsung dan belanja tidak langsung pada sektor kesehatan. Hal tersebut seperti yang di ungkapkan dari hasil kajian penelitian yang dilakukan oleh Wijiyanto dkk (2015) dalam penelitiannya menjelaskan bahwa pengeluaran pemerintah pada sektor kesehatan memberikan signifikan terhadap peningkatan indeks kesehatan di Provinsi Jawa Timur.

Meningkatnya pertumbuhan indeks pembangunan manusia di Kabupaten Situbondo dari tahun 2012 sampai tahun 2016 tentunya tidak terlepas dari indeks pembentuk indeks pembangunan manusia dimana tiga indeks pembentuk IPM tersebut adalah indeks kesehatan, Indeks pendidikan, dan indeks daya beli. Perkembangan pertumbuhan indeks pembentuk IPM selama tahun 2012-2016 pada tabel berikut.

Tabel Indikator Indeks Pembangunan

Manusia Kabupaten Situbodo Selama Tahun 2012-2016

\begin{tabular}{rrrrr}
\hline Tahun & $\begin{array}{c}\text { Indeks } \\
\text { Kesehatan }\end{array}$ & $\begin{array}{c}\text { Indeks } \\
\text { Pendidikan }\end{array}$ & $\begin{array}{c}\text { Indeks } \\
\text { Daya } \\
\text { Beli }\end{array}$ \\
\hline 1 & 2012 & 0.74 & 0.51 & 0.64 \\
\hline 2 & 2013 & 0.74 & 0.53 & 0.65 \\
\hline 3 & 2014 & 0.74 & 0.55 & 0.65 \\
\hline 4 & 2015 & 0.74 & 0.55 & 0.66 \\
\hline 5 & 2016 & 0.74 & 0.55 & 0.67 \\
\hline
\end{tabular}

Sumber: Badan Pusat Statistik Kabupaten Situbondo, 2017

Dari tabel diatas terlihat bahwa indeks pendidikan dan daya beli memiliki trend yang baik selama tahun 2012-2016 terus meningkat, akan tetapi pada indeks kesehatan tidak mengalami perubahan hal tersebut juga tidak terlepas dari beberapa indikator yang mempengaruhi pada sektor kesehatan seperti pelayanan. akses kesehatan dan pengeluaran pemerintah dalam peningkatan angka indeks kesehatan. dalam penelitan yang dilakukan oleh Radianto (2015) menjelaskan bahwa strategi yang digunakan dalam meningkatkan indeks kesehatan adalah pelayanan kesehatan dan promosi kesehatan sebagai strategi dalam meningkatkan indeks kesehatan dalam pembangunan manusia di Kabupaten Kepulauan Anambas.

Dengan pentingnya peran indeks kesehatan sebagai salah satu indeks pembentuk IPM maka paper ini mengangkat tema strategi sektor kesehatan dalam indeks pembangunan manusia di Kabupaten Situbiondo dengan batasan pembahasan paper pada sintesa strategi peningkatan indeks kesehatan di Kabupaten Situbondo. Dengan melihat pentingnya dalam meningkatkan pembangunan manusia di Kabupaten Situbondo yang merupakan salah satu tujuan capaian keberhasilan dari pembangunan. Oleh karena itu, 
perencanaan pembangunan di Kabupaten Situbondo selanjutnya mengupayakan dalam meningkatkan kesejahteraan masyarakat yang lebih baik di masa akan datang perlunya membuat perencanaan dalam bentuk strategi-strategi untuk meningkatkan indeks pembangunan manusia (IPM) pada indeks kesehatan di Kabupaten Situbondo. Rumusan masalah pada paper sebagai berikut: Bagiamanakah sintesa strategi sektor kesehatan dalam meningkatkan indeks pembangunan manusia (IPM) di Kabupaten Situbondo?

Tujuan penelitian ini untuk memformulasikan strategi dalam meningkatkan indeks pembangunan manusia (IPM) di Kabupaten Situbondo pada sektor kesehatan. Penelitian ini akan menghasilkan design strategi yang dibutuhkan untuk dapat meningkatkan pembangunan manusia pada sektor kesehatan dengan harapan dapat meningkatkan kesejahteraan masyarakat di Kabupaten Situbondo.

\section{KAJIAN PUSTAKA}

\section{a. Teori Desentralisasi Fiskal}

Secara teoritis desentralisasi merupakan penyerahan dari otoritas dan fungsi pemerintah pusat atau nasional kepada pemerintah daerah atau pemerintah sub nasional (The World Bank Grub, 2004). Disentralisasi dimaksukan adalah penyerahan wewenang pemerintahan dari pemerintah pusat kepada pemerintah daerah untuk mengatur dan mengurus urusan pemerintah di daerah masingmasing, disentralisasi sendiri di Indonesia dikenal dengan otonomi daerah. Tujuan dari desentralisasi fiskal adalah supaya pemerintah daerah dapat meningkatkan kesejahteraan masyarakat yang ada di daerahnya dengan peningkatan pelayanan publik (Suwandi, 2007). Dalam pelaksanaan disentralisasi fiskal terdapat 3 asas yang perlu di perhatikan menurut Nurkholis dan Brojonegoro (2003), yaitu:

1)Asas desentralisasi merupakan penyerahan wewenang dari pemerintah pusat ke pemerintah daerah untuk mengatur dan mengurus kepentingan masyarakat yang ada di daerah $t$ untuk mengatur dan mengurus kepentingan masyarakat yang ada di daerah tersebut menurut prakarsa yang berdasarkan aspirasi masyarakat sesuai undangundang.

2)Asas dekonsentrasi merupakan pelimpahan wewenang dari pemerintah pusat kepemerintah daerah sebagai wakil pemerintah pusat di daerah.

3) Asas tugas pembantuan merupakan penugasan pemerintah pusat kepada pemerintah daerah untuk melaksanakan tugas tertentu yang disertasi pembiayaan, sarana dan prasarana serta sumber daya manusia dengan kewajiban melaporkan dan mempertanggungjawabkan pelaksanaannya.

Menurut Mardiasmo

menjelaskan bahwa fungsi utama kebijakan disentralisasi fiskal yaitu untuk meningkatkan kualitas dan kuantitas pelayanan publik dan kesejahteraan rakyat, serta terciptanya efektifitas dan efisiensi pengelolaan sumber daya dan menciptakan ruang bagi masyarakat dalam hal ini partisipasi masyarakat dalam proses pembangunan. Fungsi distribusi dan stabilisasi pada umumnya lebih efektif dilaksanakan oleh pemerintah pusat, sedangkan fungsi alokasi oleh pemerintah daerah.

\section{b. Indeks Pembangunan Manusia}

Menurut UNDP indeks pembangunan manusia dibangun melalui pendekatan 3 dimensi dasar yaitu: 1) Umur panjang dan hidup sehat, 2) Pengetahuan, 3) Standar hidup layak. Pengertian IPM yang dikeluarkan oleh UNDP yang menyatakan bahwa Indeks Pembangunan Manusia (IPM) atau Human Development Indeks (HDI) merupakan salah satu pendekatan untuk mengukur tingkat keberhasilan pembangunan manusia. IPM dihitung berdasarkan data yang dapat menggambarkan keempat komponen yaitu angka harapan hidup yang mewakili bidang kesehatan, angka melek huruf dan rata-rata lamanya bersekolah mengukur capaian pembangunan di bidang pendidikan, dan kemampuan daya beli/paritas daya beli (PPP) masyarakat 
terhadap sejumlah kebutuhan pokok yang dilihat dari rata-rata besarnya pengeluaran perkapita sebagai pendekatan pendapatan yang mewakili capaian pembangunan untuk hidup layak.

Metode dalam pengukuran indeks pembangunan manusia saat ini menggunakan metode tahun 2014, adapaun indikator yang digunakan dalam IPM metode tahun 2014 (Badan Pusat Statistik, 2017), yaitu:

a. Angka Harapan Hidup Saat Lahir AHH (Life Expectancy - e0)

Angka Harapan Hidup Saat Lahir dihitung dari hasil sensus dan survei kependudukan. Angka harapan hidup merupakan indikator pada dimensi kesehatan, rumus AHH yaitu:

$$
\mathrm{I}_{\text {Kesehatan }}=\frac{\mathrm{AHH}-\mathrm{AHH}_{\text {min }}}{\mathrm{AHH}_{\text {maks }}-\mathrm{AHH}_{\text {min }}}
$$

Dalam perhitungan angka harapan hidup, nilai standar yang dikeluarkan oleh UNDP dan BPS, yaitu: nilai minimum 20 dan maksimum 85.

\section{b. Rata-rata Lama Sekolah - RLS (Mean Years of Schooling - MYS}

Rata-rata Lama Sekolah dihitung dalam penghitungan rata-rata lama sekolah adalah penduduk berusia 25 tahun ke atas. Rata-rata lama sekolah merupakan indikator dari dimensi pendidikan, rumus RLS yaitu:

$$
I_{R L S}=\frac{R L S-R L S_{\text {min }}}{R L S_{\text {maks }}-R L S_{\text {min }}}
$$

Dalam perhitungan rata-rata lama sekolah, nilai standar yang dikeluarkan oleh UNDP dan BPS, yaitu: nilai minimum 18 dan nilai maksimum 18.

c. Angka Harapan Lama Sekolah - HLS (Expected Years of Schooling - EYS)

Angka Harapan Lama Sekolah dihitung untuk penduduk berusia 7 tahun ke atas. HLS dapat digunakan untuk mengetahui kondisi pembangunan sistem pendidikan di berbagai jenjang yang ditunjukkan dalam bentuk lamanya pendidikan (dalam tahun) yang diharapkan dapat dicapai oleh setiap anak. Angka harapan lama sekolah merupakan indikator dari dimensi pendidikan, rumus HLS yaitu:

$$
\mathrm{I}_{\mathrm{HLS}}=\frac{\mathrm{HLS}-\mathrm{HLS}_{\mathrm{min}}}{\mathrm{HLS}_{\mathrm{maks}}-\mathrm{HLS}_{\min }}
$$

Dalam perhitungan angka harapan lama sekolah, nilai standar yang dikeluarkan oleh UNDP dan BPS, yaitu: nilai minimum 18 dan nilai maksimum 18 .

Maka dari perhitungan kedua indikator dalam dimensi pendidikan dijumlahkan untuk mengetahui jumlah keseluruhan nilai dari dimensi pendidikan, dengan menggunakan rumus perhitungan sebagai berikut:

$$
\mathrm{I}_{\text {pendidikan }}=\frac{\mathrm{I}_{\mathrm{HLS}}-\mathrm{I}_{\mathrm{RLS}}}{2}
$$

Berdasarkan penjumlahan kedua indikator tersebut maka bisa didapatkan gambaran pendidikan dan perubahan yang terjadi setiap tahunnya.

\section{d. Pengeluaran per Kapita Disesuaikan \\ Pengeluaran per kapita yang} disesuaikan ditentukan dari nilai pengeluaran per kapita dan paritas daya beli (Purcashing Power Parity-PPP). Ratarata pengeluaran per kapita setahun diperoleh dari Susenas, dihitung dari level provinsi hingga level kab/kota. Rata-rata pengeluaran per kapita dibuat konstan/riil dengan tahun dasar $2012=100$. Perhitungan paritas daya beli pada metode baru menggunakan 96 komoditas dimana 66 komoditas merupakan makanan dan sisanya merupakan komoditas nonmakanan. Metode penghitungan menggunakan Metode Rao, yaitu:

$$
\mathrm{PPP}_{\mathrm{j}}=\prod_{i=1}^{m}\left(\frac{P i j}{P i k}\right)^{1 / m}
$$

Dan rumus yang digunakan untuk menghitung dimensi pengeluaran, yaitu:

$$
=\frac{\mathrm{I}_{\text {pengeluaran }}(\text { pengeluaran })-\operatorname{In}\left(\text { pengeluaran }_{\text {min }}\right)}{\text { In }\left(\text { Pengeluaran }_{\text {maks }}\right)-\text { In }(\text { Pengeluaran })_{\text {min }}}
$$

Dalam perhitungan pengeluaran per kapita, nilai standar yang dikeluarkan oleh UNDP dan BPS, yaitu: nilai minimum Rp. 1.007.436 dan nilai maksimum $\mathrm{Rp}$. 26.572.352.

\section{c. Analytical Hierarchy Process}

AHP adalah suatu metode pengambilan keputusan yang sederhana 
dan fleksibel yang menampung kreativitas dalam rancangannya terhadap suatu masalah. Analisis AHP ditujukan untuk membuat model permasalahan yang tidak terstruktur dan biasanya diterapkan untuk memecahkan masalah-masalah terukur maupun masalah-masalah yang memerlukan pendapat (judgement). Penilaian AHP memerlukan para pakar sebagai responden dalam pengambilan keputusan dalam pemilihan alternatif. Para pakar disini merupakan orang-orang kompeten yang benar-benar menguasai, mempengaruhi pengambilan kebijakan atau benar-benar mengetahui informasi yang dibutuhkan. Untuk jumlah responden dalam metode AHP tidak memiliki perumusan tertentu, namun hanya ada batas minimum yaitu dua orang responden. AHP telah banyak digunakan oleh para pengambil keputusan untuk membantu memecahkan masalah yang kompleks. AHP dapat digunakan untuk pengambilan keputusan seperti: menetapkan prioritas, menghasilkan seperangkat alternatif, memilih alternatif, memilih alternatif kebijakan yang terbaik, menetapkan berbagai persyaratan, mengalokasikan sumber daya, meramalkan hasil dan menaksir risiko, mengukur prestasi, merancang sistem, merencanakan dan memecahkan konflik, Saaty (2000).

\section{d. Studi terdahulu}

Pada paper ini beberapa studi terdahulu yang diambil sebagai acuan yaitu: 1) Endang Septiatuti yang meneliti tentang Strategi Pemerintah Kabupaten Siak dalam Meningkatkan Indeks Pembangunan Manusia tahun 2011-2016, metode yang digunakan kualitatif, hasil penelitiannya dalam meningkatkan derajat kesehatan di Kabupaten Siak dengan meningkatkan kualitas pelayanan kesehatan ibu dan anak serta meningkatkan kuantitas pelayanan kesehatan. 2) Imam Radianto Anwar Ssetia Putra meneiliti tentang Pembangunan Manusia Kabupaten Kepulauan Anambas, metode yang digunakan deskriptif kuantitatif, hasil penelitiannya strategi peningkatan indeks kesehatan ketersediaan infrastruktur pelayanan kesehatan dan promosi kesehatan.

\section{METODE PENELITIAN}

Analisis data yang digunakan dalam penelitian ini berdasarkan pada rumusan permasalahan metode analisis data yang digunakan metode AHP sebagai suatu alat untuk memecahkan persoalan. Metode ini merupakan metode analisis dari hasil data kualitatif yang dikuantitatifkan sehingga tersusun menjadi sebuah model formulasi yang didapatkan dari hasil penilaian responden dari beberapa pilihan yang dianggap prioritas dari beberapa pilihan.

Data yang digunakan dalam penelitian ini berupa data primer yang diperoleh dari hasil wawancara, serta data sekunder dari instansi terkait yang berkaitan dengan IPM dari tahun 2012-2016. Responden dalam pengambilan data primer, dipilih secara 'purposive sampling' dimana pemilihan responden berdasarkan kriteria yang tepat/tertentu. Pelaksanaan penelitian terdiri atas: (1) penetapan faktor-faktor dalam meningkatkan IPM, (2) perumusan kerangka pendekatan dan identifikasi indikator-indikator utama; (3) penetapan faktor-faktor yang mempengaruhi peningkatan Indeks Pembangunan Manusia sektor kesehatan;

penyusunan/perancangan kuesioner untuk pengumpulan data primer untuk masingmasing instansi, yang meliputi kuesioner Indeks Pembangunan Manusia sektor kesehatan; (5) pelaksanaan survey lapangan dan pengumpulan data sekunder; (6) tabulasi data dan analisis data/informasi; (7) penyusunan sintesa akhir strategi dalam meningkatkan IPM sektor kesehatan di Kabupaten Situbondo.

\section{HASIL DAN PEMBAHASAN}

Berdasarkan hasil analisis AHP yang digunakan sebagai desain strategi sektor kesehatan untuk meningkatkan indeks pembangunan manusia di Kabupaten Situbondo berdasarkan hasil wawancara dan pembobotan prioritas dari beberapa pilihan yang ditentukan. Berikut adalah hasil analisis AHP Sektor Kesehatan sebagai berikut 
Tabel Pembobotan Strategi Peningkatan IPM Sektor Kesehatan di Kabupaten Situbondo.

\begin{tabular}{|c|c|}
\hline $\begin{array}{l}\text { Strategi Peningkatan IPM Sektor } \\
\text { Kesehatan }\end{array}$ & Nilai \\
\hline \multicolumn{2}{|c|}{ Hirarkhi Level I : Tujuan Perencanaan } \\
\hline 1. Sarana dan Prasarana Kesehatan & 0.465 \\
\hline 2. Akses Kesehatan Masyarakat & 0.352 \\
\hline 3. Program Sektor Kesehatan & 0.189 \\
\hline \multicolumn{2}{|c|}{$\begin{array}{l}\text { Hirarkhi Level II : Instrumen Perencanaan } \\
\text { 1a. Tenaga kesehatan }\end{array}$} \\
\hline $\begin{array}{l}\text { 1b. Standart layanan kesehatan } \\
\text { 1c. Posko layanan Kesehatan }\end{array}$ & 0.352 \\
\hline & 0.214 \\
\hline 3a. Program kesehatan & \\
\hline 3b. Kampanye kesehatan & 0.187 \\
\hline \multicolumn{2}{|c|}{$\begin{array}{l}\text { Hirarkhi Level III : Formulasi Strategi } \\
\text { peningkatan IPM Sektor Kesehatan }\end{array}$} \\
\hline 1.Pelayanan kesehatan & 0.136 \\
\hline 2. Anggaran kesehatan & 0.059 \\
\hline 3. Kelembagaan sektor kesehatan & 0.018 \\
\hline Inconsistency Index & 0,580 \\
\hline
\end{tabular}

Sumber : Dihitung Dari Survey Lapangan, 2017

Dari hasil analisis AHP diatas diketauhi bahwa desain strategi yang digunakan sebagai strategi dalam meningkatkan indeks pembangunan manusia di Kabupaten Situbondo menggunakan strategi pada pelayanan kesehatan sebagai strategi prioritas dalam meningkatkan IPM di sektor kesehatan di Kabupaten Situbondo karena nilai hasil pembobotan akhr dari hasil analisis AHP sebesar 0,136, dan desain strategi kedua anggaran sektor kesehatan sebesar 0,059, yang ketiga kelembagaan sektor kesehatan sebesar 0,018. Desain strategi dari hasil AHP diatas dapat dijelaskan berdasarkan urutan yang telah dipilih berdasarkan prioritas pembobotan oleh responden sebagai berikut.

Tabel desain strategi dalam meningkatkan

IPM sektor kesehatan di Kabupaten

Situbondo

\begin{tabular}{|c|c|c|c|}
\hline \multicolumn{5}{|c|}{ Desain Startegi Peningkatan IPM Sektor } \\
Kesehatan \\
\hline
\end{tabular}

\begin{tabular}{|c|c|c|c|}
\hline & & & $\begin{aligned} & \text { layanan } \\
& \text { kesehatan. } \\
& \checkmark \text { sarana } \\
& \text { layanan } \\
& \text { kesehatan. }\end{aligned}$ \\
\hline 2 & $\begin{array}{l}\text { Anggaran } \\
\text { kesehatan }\end{array}$ & 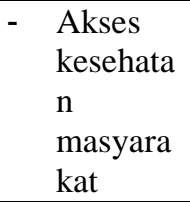 & $\begin{aligned} \checkmark & \text { Pembiaya } \\
& \text { an } \\
& \text { kesehatan } \\
\checkmark & \text { Akses } \\
& \text { kesehatan }\end{aligned}$ \\
\hline 3 & $\begin{array}{l}\text { Kelembagaa } \\
\text { n sektor } \\
\text { kesehatan }\end{array}$ & 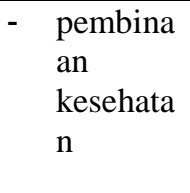 & $\begin{array}{ll}\checkmark & \text { Program } \\
& \text { kesehatan } \\
\checkmark & \text { Kampany } \\
& \text { e } \\
& \text { kesehatan }\end{array}$ \\
\hline
\end{tabular}

Sumber : Hasil pembobotan AHP, 2017

Pelayanan kesehatan merupakan

strategi utama dalam meningkatkan indeks pembangunan manusia di Kabupaten Situbondo dengan sasaran perencanaan dengan penyediaan sarana dan prasarana kesehatan yang baik dan sesuai kepada masyarakat, indikator yang digunakan dalam pelayanan kesehatan ini adalah tenaga kesehatan dimana jumlah rasio tenaga kesehatan dengan jumlah masyarakat harus sesuai, di Kabupaten Situbondo rasio tenaga kesehatan dengan rasio jumlah masyarakat masih rendah maka perlunya menambah jumlah tenaga kesehatan, memperbaiki layanan kesehatan yang sesuai standart layanan kesehatan karena masih minimnya peralatan kesehatan yang ersedia di unit-unit pelayanan kesehatan yang ada, sarana layanan kesehatan yang masih belum mencakup seluruh wilayah bagian di Kabupaten Situbondo karena keterbatan sarana layanan kesehatan yang ada seperti posko-posko unit kecil layanan di desa dan juga pembangunan fasilitas kesehatan umum seperti toilet bersih di desa-desa.

Strategi kedua dalam meningkatkan indeks pembangunan manusia di Kabupaten Situbondo adalah anggaran kesehatan dengan sasaran perencanaan akses kesehatan masyarakat dimana indikator yang digunakan adalah pembiayaan kesehatan dengan pemberian subsidi palayanan kesehatan kesehatan dan harga obat yang murah untuk masyarakat tidak mampu, menambah akses kesehatan 
yang di peruntukkan untuk di desa-desa seperti unit kendaraan pelayanan kesehatan dengan harapan dapat mengatasi masalah pelayanan kesehatan dengan jarak yang cukup jauh dari posko pelayanan kesehatan.

Strategi yang terakhir atau ketiga adalah meningkatkan peran kelembagaan sektor kesehatan dalam meningkatan tingkat kesehatan di Kabupaten Situbondo dengan sasaran pembinaan kesehatan kepada masyarakat melalui indikator program pengentasan penyakit yang mengalami kenaikan dalam jumlah pasien yang terkena dampak dari penyakit tersebut, serta mengadakan kampanye dan penyuluhan kesehatan di seluruh wilayah desa, wilayah pesisir dan kota dalam meningkatkan taraf kesehatan masyarakat yang ada di Kabupaten Situbondo.

\section{KESIMPULAN DAN SARAN a. Kesimpulan}

Berdasarkan hasil analisis dan pembahasan hasil analisis maka dapat disimpulkan bahwa strategi dalam meningkatan indeks pembangunan di Kabupaten Situbondo pada sektor yang pertama strategi meningkatkan pelayanan di sektor kesehatan, kedua strategi anggaran pada sektor kesehatan dalam memberikan bantuan dan subsidi di sektor kesehatan, ketiga strategi peran lembaga sektor kesehatan dalam pembinaan kesehatan di masyarakat.

\section{b. Saran}

perlunya perhatian lebih dari pemerintah Kabupaten Situbondo dalam penyediaan sebaran layanan kesehatan sehingga dengan mudahnya layanan kesehatan yang dapat dijangkau oleh seluruh lapisan masyarakat serta meningkatkan kampanye kesehatan di masyarakat tentang pengetahuan kesehatan sehingga perencanaan dalam meningkatkan indeks kesehatan di Kabupaten Situbondo dapat tercapai sesuai target rencana yang di jalankan.

\section{DAFTAR PUSTAKA}

Arisandi, Winda. 2015. Strategi dinas kesehatan dalam meningkatkan kualitas pelayanan kesehatan melalui metode CSR (Citizen Report Card)di Kota Surabaya. Kebijakan dan Manjemen Publik. 3 (2): 12-23.

Badan Pusat Statistik Indonesia. 2017. Indeks Pembangunan manusia. Jakarta

Badan Pusat Statistik Kabupaten Situbondo. 2017. Kabupaten Situbondo dalam angka 2017. Kabupaten Situbondo

Mardiasmo, 2004, Otonomi dan Manajemen Keuangan Daerah. Andi. Yogyakarta.

Nurkholis dan Brojonegoro, Bambang PS. 2003. Dampak Desentralisasi Fiskal Terhadap Perekonomian Antar Daerah. Jurnal Ekonomi dan Pembangunan Indonesia FEUI. 3 (2).

Pasaribu, Riada Marenny. 2015. Solusi dalam mengatasi masalah pembangunan kesehatan masyarakat di Indonesia. Jurnal Ilmiah Đunia Ilmu”. 1 (2): 1-9.

Putra, Imam Anwar Setia. 2015. Pembangunan manusia Kabupaten Kepulauan Anambas. Urnal Bina Praja. 7 (2): 173-184.

Saaty, Thomas L.,. 2000. Fundamental of Decision Making and Priority Theory with The Analytic Hierarchy Process. Pittsburgh: RWS Publication.

Septiatusi, Endang. 2018. Strategi pemerintah Kabupaten Siak dalam meningkatkan indeks pembangunan manusia tahun 2011-2016. JOM FISIP. 5 (1): 1-11.

Suripto. 2011. Pembangunan manusia untuk mewujudkan masyarakat Kalimantan Timur berkualitas. Jurnal Borneo Administrasi. 7 (3): 258-282.

Suwandi, Made, 2007. "The Grand Strategy of Promoting Decentralization in Indonesia". dalam International Seminar Decentralization "Six Year of 
Indonesia's Decentralization. Jakarta.

UNDP. 1990. Human Development Report. New York: Oxford University Press.

UNDP. 1996. Economic Growth and Human Development. Human Development Reports 1996. New York: Oxford University Press.

UNDP. 2000. Human Right and Human Development. Human Development Reports 2000. New York: Oxford University Press.

UNESCO/Human Development Report 2002, http;//www.undp.org/ hdr2002/indicator/pdf/hdr_2002_ta ble_9.pdf.

Wijayanto, Anang. Khusuani, Moh. Syafitri, Wildan. 2015. Analisis pengaruh pengeluaran kesehatan dan pendidikan seta PDRB per kapita terhadap indeks pembangunan manusia (studi terhadap kabupaten/kota di Jawa Timur. International Journal of Social and Local Economic Governance (IJLEG). 1 (2): 85-95.

World Bank. 2004. Measure ZFiscal Desentralization.Data Note Decentralization and Subnational Regional Economics Thematic Group, World bank. Washington DC, August 2004 